DOI: 10.1515/ausfm-2015-0017

\title{
Memento and the Embodied Fabula: Narrative Comprehension Revisited
}

\author{
Steffen Hven \\ Bauhaus-Universität Weimar (Germany) \\ E-mail: steffenhven@gmail.com
}

\begin{abstract}
Although Christopher Nolan's Memento (2000) has been the subject of numerous critical examinations, the unique manner in which the film's reverse-chronological dramaturgy interweaves the spectators' cognitiveanalytical attempts to ensure causal-linear coherency together with a corporalaffective sensation of temporal loss remains underexplored. This I believe is due to the inability of prevalent narratological terms of cutting across the current divide and uniting on the same conceptual plane the cinematic spheres of the cognitive-analytical, evaluative, and interpretative, on the one hand, with the visceral, haptic, and sensory-affective, on the other hand. As an attempt to carve out a conceptual ground where these key facets of the cinematic experience can be unified in a nonhierarchical and nonreductive manner, I propose an embodied reconceptualization of the cognitive-formalist concept of the fabula. In order to do so, however, it is necessary to dispute a series of dominant assumptions about cinematic spectatorship and narrative comprehension that automatically come with this narratological concept. ${ }^{1}$
\end{abstract}

Keywords: narratology, cognitive film science, embodied cognition, filmphilosophy, the embodied fabula.

\section{Memento and the Embodied Fabula: Narrative Comprehension Revisited}

The brilliance of Christopher Nolan's Memento (2000) lies not simply in its complex narrative dramaturgy. It equally pertains to how this evokes in the viewers an

1 This article draws upon research conducted as part of my PhD-dissertation Embodying the Fabula: Cinema between the Lines at the Bauhaus-Universität Weimar, Germany. I would like to express my gratitude to my supervisors Lorenz Engell and Christian Kassung for their comments, guidance, and critical remarks, and to the Graduiertenförderung des Freistaates Thüringen for financial support. I would also like to express my appreciation to two anonymous reviewers of an earlier draft of this paper for their thoughtful comments and for suggesting ways to further strengthen the concept of the embodied fabula. 
embodied sensation of time that mirrors that of the film's main character Leonard Shelby (Guy Pearce), who suffers from anterograde amnesia. Although generally hailed as a landmark in nonlinear storytelling, Memento compels its viewers to be more engaged with linear reasoning than most classical Hollywood narratives. Consequently, the film renders visible the inferential nature of cognition and perception and thus envisages the cinematic spectator as an active participant constructing - rather than passively receiving - narrative sense. Noticing this aspect of the film, Robert Sinnerbrink observes that Memento "chimes with cognitivist theories of narrative that emphasise the roles of rational inference-making, the testing and adjusting of beliefs, and the cognitive matching of affective tone with perceptual awareness" $(2011,48)$. Yet, due to its ability to distort our sense of temporality, Memento also poses a challenge to theories of cinematic spectatorship based on cognitive appraisals, evaluations, and interpretations, ${ }^{2}$ because it explicates the emotional and affective underpinnings of narration (cf. Hogan 2012).

Memento's film-philosophical exploration of how spectators construct a narrative world or environment thus forces us to reconsider the cognitive and representational dominance within narratology. ${ }^{3}$ Of special interest to this article is how the film provokes a reconsideration of the cognitive-formalist revitalization of the Russian formalists' narratological distinction between the fabula (the story's state of affairs and events as inferred by the viewer and organized into a chronological and casual order) and the syuzhet (the actual arrangement of the visible and audible events in the narrative) (Bordwell 2007, 14). However, it shall be argued that the fabula does not arise from a cognitive picking up of relevant cues inherent in the film's syuzhet, but from a resonance created between film and spectator that activates feedback loops in the perceptual, emotional, affective, cognitive, and sensory-motor circuits. ${ }^{4}$

2 In brief, the cognitive appraisal theory of emotion argues that people's personal interpretations of a given event is determining for their emotional reaction (cf. Lazarus 1984). In film theory, such a perspective is typically assumed by cognitive-formalist theories on narrative comprehension and emotion (cf. Plantinga 2009; Plantinga and Smith 1999b; Tan 1996).

3 Although this article emphasizes their interdependence, it is useful to draw a conceptual distinction between cognition, emotion, and affect. While the term cognition "collectively refers to a variety of higher mental processes such as thinking, perceiving, imagining, speaking, acting and planning" (Ward 2010,4), it is primarily used to designate mental activities associated with informationprocessing, judgements, evaluations, attention, and problem-solving. The differentiation between emotion and affect is more problematic, as cognitivists generally do not draw such a distinction. However, I believe it to be useful to reserve the term emotion for subjective and object-oriented feelings. Affect, on the other hand, cannot be simply attached to a particular feature or object and thus lacks a specific cause or basis in the world or film (cf. Yacavone 2015, 171).

4 A model of such resonances has been suggested by Torben Grodal's PECMA-flow (perception, emotion, cognition, motor action) (cf. Grodal 2009). In addition, Vittorio Gallese's embodied 
In performing a reconceptualization of the cognitive-formalist concept of the fabula, this article is informed by a steadily growing body of works that carve out the embodied nature of the cinematic experience. ${ }^{5}$ It is, however, crucial that the increased focus on the cinematic body does not amount to a reversal of the mindbody dichotomy of classical cognition such that the affective is conceptualized as an autonomous sphere to be studied in isolation from higher cognitive processes and hermeneutic analysis. ${ }^{6}$ On this ground, the embodied fabula is a conceptual tool answering the plead of William Brown to synthesize "with the haptic, or affective, elements of the cinematic experience the 'higher' 'brain' elements that in fact form a continuum with them" $(2013,141)$.

\section{Linearity and Nonlinearity: Memento's Exploration of Cinema's Temporal Modalities}

Memento perfectly illustrates the affect-emotion-cognition continuum which becomes activated as the spectators embody the cinematic world unfolding before them. The film motivates viewers to perform the cognitive processes described by David Bordwell and others, while simultaneously demonstrating how cognition, and consequently narrative comprehension, is co-constituted in corporal affects and emotional responses to the cinematic event. In introducing the concept of the embodied fabula, this article attempts to incorporate into a common conceptual framework the film's activation of a (narrative) desire for causal-linearity, our corporal-mental efforts to achieve such, and our sensory-affective temporal

simulation theory - based on research in the mirror neuron system - provides a model for the intimate connection between the audiovisual stream of images and the brain-body (cf. Gallese and Guerra 2012; for a similar theory based on literature cf. Gallese and Wojciehowski 2011).

5 Works that re-emphasize the role of embodiment in cinema include: Barker 2009; Elsaesser and Hagener 2009; Marks 2000; Marks 2002; Shaviro 1993; Sobchack 2004; Grodal 2009; Gallese and Guerra 2012.

6 In recent years, the concept of affect has been principal for the formulation of a more direct encounter between the spectator and the moving images (cf. Deleuze 2005a; Deleuze 2005b; Pisters 2012; Shaviro 1993; Sobchack 1992). Affect, particularly as it is has been elaborated in the work of Brian Massumi, can be differentiated from cognition and emotion, which we have or possess, since it is nonconscious, asignifying, presubjective, unqualified, and intensive; and thus not to be attributed to a self-identical Cartesian individual $(2002,23-45)$. Affect is thus "irreducibly bodily and autonomic" $(2002,27)$. Although I find Massumi's distinction between emotion and affect useful, I am sceptical towards a radical disconnection of affect from the emotional and cognitive sphere. The problem with such a disjunction is that it utilizes the concept of affect to inverse the Cartesian dualism separating affect (body) from cognition (mind) (cf. Leys 2011). See Brinkema (2014) for a recent intervention in the study of affect that does not oppose this concept to critical inquiry, interpretation, and formal and aesthetic concerns. 
disorientations that arise from such attempts to master the narrative. ${ }^{7}$ As it shall become evident, this procedure is not straightforward, given that an embodied reconceptualization of the fabula gestures towards a broader redefinition of the concept of narration. ${ }^{8}$ In order to understand this claim better, it is useful to consider how Memento both invokes and challenges the way the cognitiveformalist fabula copes with narrative temporality.

Once confronted with the idea of Memento being a nonlinear film, Christopher Nolan promptly answered as follows: "You referred to the film as non-linear but in fact it's very linear just in reversed chronology" (Nolan 2012). In fact, the linear nature of the film is made explicit on the special edition of the DVD-version, since it includes a chronologically re-edited version of the film. The re-edited version reveals how meticulously the film has been constructed to accentuate the causallinear relation of the individual scenes. Following the suggestion of film critic Andy Klein (2001), the narrative structure can be illustrated according to an intricate yet systematic scheme where the coloured, reverse chronological scenes (A, B, C, etc.) are separated from the black-and-white, chronological scenes (1, 2, 3, etc.). Klein's suggestion provides us with the following visualization of the narrative structure:

Credits, 1, V, 2, U, 3, T, 4, S, 5, R, 6, Q, 7, P, 8, O, 9, N, 10, M, 11, L, 12, K, 13 J, 14, I, 15, H, 16, G, 17, F, 18, E, 19, D, 20, C, 21, B, 22/A.

Each reverse chronological sequence is interrupted by a black-and-white scene from which a new reverse chronological sequence follows, etc. Scene $22 / A$ is pivotal in relation to this, since this is where the two narrative threads merge. The black-and-white scene 22, as Klein observes, "almost imperceptibly slips into color and, in an almost vertiginous intellectual loop, becomes (in real-world order) scene A, the first of the color scenes" (Klein 2001).

7 For an alternative attempt to synthesize the affective and cognitive aspects of narrative comprehension see Daniel Yacavone's Film Worlds: A Philosophical Aesthetics of Cinema (2015).

8 While this article centres on how the notion of embodiment allows us to expand the concept of the fabula, such an approach inevitably gestures at a broader embodied rethinking of narratology beyond the scope of this article. If the fabula, as this article suggests, grows out of our embodied experience with the film, this concept is misconceived as a causal-linear and representational string of events that can be isolated from the spectator's corporal-affective and emotional experience and construction of these events. The pertinent task becomes to describe the continuum between corporal experiences and higher-order representations. One possible place to start is to expand upon the argument made by George Lakoff and Mark Johnson in relation to reason into the field of narratology. In this fashion, not only reason but also cinematic narration must depart with disembodiment but be seen as arising from the nature of embodied experience (and our engagement with the environment). As the authors declare, "[t]his is not just the innocuous and obvious claim that we need a body to reason [and, I add, to construct narratives]; rather, it is the striking claim that the very structure of reason [and, I add, cinematic narratives] itself comes from the details of our embodiment" (Lakoff and Johnson 1999, 4). 
With the merging of the two narrative threads, the film allows for the cognitive construction of a unified causal-chronological continuum (the cognitive-formalist fabula), which can be translated into the following structure:

1, 2, 3 ,4 ,5, 6, 7, 8, 9, 10, 11, 12, 13, 14, 15, 16, 17, 18, 19, 20, 21, 22/A, B, C, D, E, F, G, H, I, J, K, L, M, N, O, P, Q, R, S, T, U, V, Credits (in reverse).

In applying this narrative logic, Klein continues by providing an extensive and meticulous account of the film's events once these have been organized causallinearly.

However useful Klein's visualization of Memento's narrative structure may be, it also exemplifies the gap existing between "our actual experience of the cinema and the theory that we academic film scholars construct to explain it" (Sobchack 2004, 53). If we consider the aforementioned re-edited version of Memento, it becomes clear that it does not merely allow spectators to experience the film without the obstructions pertaining to the original version; in absentia, it also testifies to the surplus value of the original. From the perspective of Klein's visualization of Memento's narrative (corresponding to Bordwell's cognitiveanalytical fabula), the narrative events of the film remain the same in both versions, yet anyone who has watched both versions of Memento is likely to have had two qualitatively different experiences of those events. Logically, both versions focus their narrative attention on Leonard's memory system - consisting of mementos in the form of annotated photographs, notes, and tattoos for the most important facts -, yet, only the original version of the film is capable of provoking a matching feeling of temporal disorientation in the spectators.

The surplus value of the original version pertains to a nonlinear dimension of Memento, which is not captured by the cognitive-formalist fabula. ${ }^{9}$ In an interview published shortly after the film's initial release, Christopher Nolan himself points to the nonlinear quality of the film: "The whole idea was to make a film that bled into the mind a little bit, spun in your head, that you constructed very much yourself. And when I listen to [Radiohead's album Kid A], no matter how many times I listen to it, I don't know what comes next" (Nolan in Timberg $2001,14)$. Once our narrative comprehension is attuned to "the construction of a

9 For clarification, I do not use the term nonlinear to refer to the film's reverse-chronological telling, but to those aspects of the film which can neither be said to have a specific cause in the film nor to remain qualitatively unaffected once the narrative events have been temporally rearranged. In brief, complexity theory holds that the overall behaviour of a nonlinear or complex system cannot be explained by reference to the sum of its individual components. As Robert Pepperell explains, this "means that even though we may be able to break up a system into its constituent parts, we will not be able to learn about the global behaviour of the system by studying them individually" (2003, 26; see also Prigogine and Stengers 1984; Morin 2007). 
more or less intelligible story" (Bordwell 1985, 33) - the default mode assumed in most cognitivist scholarship -, this narrative dimension is easily lost, ignored, or simply deemed a disturbing side effect. ${ }^{10}$ We thus need to supplement the analytical fabula of Memento (understood as the "offline," diagrammatic, cognitive-analytical, intersubjective, and chronological reorganization of story events) with an "online," embodied counterpart capable of incorporating the qualities filtered out in brute cognitive-analytical representations of the "story."11

\section{The Fabula and the "Classical Sandwich" of Narrative Comprehension}

The cognitive-formalist fabula is constructed as spectators pick up the cues of the film by means of mental schemata, which are "abstract mental structures that organize the perceptual cues in the plot into a coherent and comprehensible mental whole" (Coëgnarts and Kravanja 2012, 87). ${ }^{12}$ In this conception, the fabula is an abstract mental entity that nonetheless dominates our perception of the cinematic material, which is being constantly (re-)interpreted to accommodate the construction of a coherent and causal-linear appropriation of the film material. Thus, not only is the fabula in this conception predisposed to causal-linearity (being a "spatiotemporal realm in which the action unfolds in chronological order" [Bordwell 2007, 110]), it participates in an ongoing linearization of how the cinematic material is experienced. Bordwell has been criticized for endorsing a too abstract conception of schemata, isolating it from both language and the body (Buckland 2003, 31). Such criticism appears particularly justified in reference to a key assumption made in Bordwell's hugely influential Narration in the Fiction Film (1985). Here the author holds that the "spectator's comprehension of the films' narrative is theoretically separable from his or her emotional responses" $(1985,30) \cdot{ }^{13}$

10 Consequently, Bordwell believes "Nolan's real achievement [...] is to make his reverse-order plot conform to classical plot structure and film-noir twists" $(2006,79)$.

11 In using the terms online and offline, I refer to a distinction made between two basic forms of cognition. Whereas online cognition refers to our immediate engagement with the environment (corresponding to our ongoing construction of the fabula during the screening of Memento), offline engagement is the more abstract, hypothetical imagining of events decoupled from the actual environment of concern (corresponding to the analytical fabula). It is crucial to note that within embodied cognition both these forms of cognition are perceived to be body-based (cf. Wilson 2002).

12 Within the cognitive sciences, schemata "are cognitive structures representing generic knowledge, i.e. structures which do not contain information about particular entities, instances or events, but rather about their general form” (Emmott and Alexander 2009, 411).

13 Yet, it shall be noted that Bordwell in later works appears more willing to accept the corporal aspect of mental schemata. This is, for instance, the case when he observes how "[m]ore and more activities seem traceable to humans' super-sensitive natural endowment [...] As research 
I will argue that this modus operandi, which mirrors what the philosopher Susan Hurley (2002) has labelled the "classical sandwich" model of cognition, also dominates cognitive approaches dealing explicitly with emotion and affect in cinema. In brief, Hurley's metaphor of the sandwich encapsulates a position within the study of cognition which "regards perception as input from world to mind, action as output from mind to world, and cognition as sandwiched between" $(2008,2)$. The core assumption that Hurley wants to criticize with the metaphor of the classical sandwich is that action, perception, and thought can be ontologically dissociated. However, as Vittorio Gallese and Hannah Wojciehowski have pointed out, in conceiving action and perception as separate modular domains, classical cognitivism neglects "both the intertwine character of perception and action and their crucial contribution to cognitive processes" $(2011,11)$.

My thesis is that the concept of fabula - when understood as an inferential and exclusively cognitive construct - occupies the role of the sandwich filling within film narratology. This is not just the underlying assumption made by Bordwell in Narration in the Fiction Film. Carl Plantinga, a prominent proponent of the cognitive-evaluative stance to emotions in cinema explains that "a cognitive approach holds that an emotional state is one in which some physical state of felt agitation is caused by an individual's construal and evaluation of his situation" (1997, 378). The advantage of this approach is that it moves beyond the Western dichotomization of emotion and reason since it allows cognitive researchers "to discuss emotion states in terms of goals, objects, characteristics, behaviors, judgements, and motivations" (Plantinga and Smith 1999a, 3). However, in focusing only on the cognitive dimension of emotions, this position risks reducing the corporal-affectivity of cinema to the cognitive-evaluation of narrative events.

As a counter-reaction to the cognitive-evaluative position, recent decades have seen an increased interest in embodiment and affect. While work conducted here has shed valuable light on the many ways affect cannot simply be subsumed under the category of cognition, it has also left a remarkable gap between cognition and affect. With the concept of the embodied fabula, the aim is to integrate both the affective and cognitive domains into a larger conceptual framework capable of capturing more fully their complex interactions, which are defining of the cinematic medium. An intriguing, yet all too often ignored aspect of Memento is how the film establishes a nonhierachical relationship between cognitivesymbolic operations (e.g. the reorganization of the narrative continuum), affective system present at birth but awaiting activation and tuning from the environment" $(2007,45)$. 
incitements (e.g. a sensation of temporal loss providing another perspective on Leonard's amnesia), and emotional involvement (e.g. the intuitive rather than rational sympathy towards Leonard's self-righteous project).

\section{From Embodied Cognition to the Embodied Fabula}

An example of the intricate manner in which cinema brings cognitive, emotional, and affective undertakings to engage can be found in how Memento on several levels instigates an alignment between Leonard and the spectator. This alignment is cognitive-epistemological, because the narrative structure restrains our knowledge in a manner comparable to how Leonard is restrained by his shortterm memory. However, this alignment also operates at a corporal-affective level, because not only is our access to information limited, we also feel limited and restrained in regards to our own memory capabilities as we are trying to work out the narrative. In addition, the alignment is sustained by classical cinematic emotional and affective markers such as facial close-ups, the musical score, camera angles, and colour schemes (cf. Renner 2006).

To exemplify the different modes of experience invoked by Memento, consider the following three viewer-reactions highlighted by Stefano Ghislotti (2003):

Viewer 1: "I've seen the movie three times now and may have to watch it ten more times until I get it all straightened out."

Viewer 2: "This movie was brilliant because it totally got me dizzy... never before can I recall concentrating so hard on what was going on... eventually, I hit a mind warp and got totally lost forgetting how things ended thus making the facts in the beginning a dizzying of feelings and a distortion of my OWN memory."

Viewer 3: "I loved this movie because it made me feel as if I had a short-term memory deficit."

These comments illustrate the interrelation between aspects of the cinematic experience that are cognitive-analytical (the straightening out of the narrative), affective-embodied (a "dizzying of feelings and a distortion of my OWN memory"), or induce cognitive-affective, i.e. embodied, reflections about the cinematic experience (as if "I had a short-term memory deficit"). Although the comments stem from three different viewers, I believe each alludes to the same interrelated experience. Whereas the cognitive-formalist fabula only accounts for the first, the embodied fabula comprises all three. 
Memento is unique since it renders evident the need to unite our corporalaffective and cognitive-analytical engagements with cinema into a nonhierarchical and recursive framework. Thus, an analysis of the cognitive activities of the spectators in reorganizing the narrative elements into a coherent fabula is incomplete without an account of how such activities interact and co-constitute the temporal sensations and disorientations that play an equal part in shaping our sense of the narrative. In turn, a description of the affective experience of the film is forced to consider the meticulous arrangement of the film's narrative design. ${ }^{14}$

In reconceptualizing the fabula as a tool situated in the direct encounter between film and spectator, we must also necessarily reinterpret the intellectual, mental, and cognitive activities of cinematic spectatorship as being embodied. The term embodied not only refers to a film theoretical interest in the body of the cinematic spectator, but also to studies that more broadly have argued for the centrality of corporal processes in relation to questions of consciousness, thinking, cognition, and the mind (e.g. Gallagher 2005; Lakoff and Johnson 1999; Varela, Thompson, and Rosch 1992). Memento provides a perfect illustration of embodied cognition because it relies heavily on how spectators perform ordinary cognitive tasks (e.g. problem-solving, temporal re-integration, logical inferences) to organize the narrative continuum in terms of causal-linearity (Ghislotti 2009), but demonstrates that these activities do not ensure an analytically-detached mode of spectatorship driven solely by cognitive evaluations, interpretations, and computations. Instead, such enterprises must be considered as mutually constitutive with more direct, embodied - sensory-motor, corporal, affective, and emotional - modes of appreciating the cinematic universe.

The term embodied thus points towards a renewed conception of narrative comprehension not constituted in the idea that we relate to the cinematic world and the characters inhabiting it primarily through "mind-reading" or mental simulation. ${ }^{15}$ Although such may play an important part in how cinematic

14 It is beyond the scope of this article to present a more comprehensive analysis of the specific nature of the cognitions, emotions, and affects that emanate from engaging with Memento's narrative. For a more detailed account of the cognitive work of the spectator and the difficulties it causes to episodic memory cf. Ghislotti (2009); for an analysis of the emotion markers instigated by the film cf. Renner (2006); and for an approach that deals with the film's affective powers, cf. Bianco (2004).

15 Here "mind-reading" refers to theories within psychology and philosophy attempting to explain how we can understand and predict the mental and emotional states, the goals, motifs, and mood of others. According to what has become known as theory theory, we are capable of this due to "our theories of folk psychology, which are made up of a set of law-like generalizations that connect various mental states with other mental states, with external circumstances, and with overt behaviour" (Coplan 2009, 104). A competing view is the simulation theory according 
worlds are experienced, they must be seen as merely components of a more encompassing process in which the spectators embody the cinematic space-time. Although Memento engages us with quite an amount of analytical backwards reasoning, it ultimately evidences how the cinematic experience "is meaningful not to the side of our bodies but because of our bodies" (emphasis in original, Sobchack 2004, 60).

To capture this process, I use the fabula-term because it more than the other competing terms (such as the story, fiction, or diegetic) emphasizes the constructivist nature of narrative comprehension. At the same time, however, I maintain that the fabula in its Bordwellian conception is used primarily to refer to a cognitive-analytical and detached conception of the "story" as something that can be theoretically isolated from the viewers' emotional and affective responses. Consequently, the fabula term is often reserved to what I have referred to as the analytical fabula. While not denying the usefulness of this term, the embodied fabula serves as a reminder that narration is a dynamic process growing out of our bodily experiences as we engage with the cinematic material. Even when we are engaged in an analytical linearization of the story to achieve a sense of spatio-temporal and causal-linear orientation within the narrative universe, our mode remains embodied insofar as the body shapes higher-level cognitions (cf. Gallagher 2005). The analytical mode of narrative comprehension that dominates cognitive-formalism is thus not eradicated, but rather subsumed into a more encompassing embodied approach to narrative comprehension. ${ }^{16}$

to which "we attempt to determine what others think, feel, and desire by simulating their mental states, that is, attempting to adopt their perspective, using our own mind to model theirs under certain conditions" (Coplan 2009, 104). Yet, I believe 'simulation' occurs not only on the higher-level of cognitive processing, but also more directly on the immediate, intuitive, preconscious, and corporal-affective level. This is the core argument of embodied simulation theory developed by Vittorio Gallese $(2005 ; 2011)$. In applying this theory to the study of cinema, Gallese and Guerra argue: "we map the actions of others onto our own motor representations, as well as others' emotions and sensations onto our own viscero-motor and sensory-motor representations" (2012, 206). In her latest article, Patricia Pisters (2014) argues convincingly for the possibility of uniting mind-reading models with embodied simulation theory for a richer understanding of how cinema generates empathy.

Although the embodied reconceptualization of the fabula is a move away from - to use Bordwell's own words - the "too-sapient viewer" (2011) of Narration in the Fiction Film (1985), his now classical narratological study nevertheless offers an advanced description of the core operations of a particular analytical attitude to cinematic narration. Defending himself against an overall disinterest in the emotional aspects of cinema, Bordwell claims that this is not problematic as long as we acknowledge that his theory is concerned with "only one aspect of our experience of narrative" $(2007,9)$. 


\section{Resituating the Fabula in the Cinematic Experience}

In simultaneously activating and disrupting the automatic and unconscious flow according to which we habitually construct our experience of a given film in causal-linear terms, Memento makes us sensitive towards temporal layers that otherwise remain imperceptible. In relation to this, it has been argued that the film can be seen as a meta-time travel story insofar as it is "not one told by cinema, but one enacted by the film-viewing experience” (Baguer 2004, 250). In turning its story about memory loss back on its viewers, Memento allows us to become cognitively, emotionally, and affectively immersed in its narrative world.

The embodied fabula reunites the cognitive-reflexive with the corporal-affective dimensions of the film-experience and, as such, exists in a realm belonging neither to the cinematic spectator nor to the film per se. In fact, the embodied fabula designates a cinematic realm in which it no longer makes sense to obtain a strict separation between these. This idea resonates with Gilles Deleuze's filmphilosophical coupling of the brain and the screen. In a famous passage, Deleuze explicates: "The brain is unity. The brain is the screen. [...] The circuits and linkages of the brain don't preexist the stimuli, corpuscles, and particles [grains] that trace them. Cinema isn't theater; rather, it makes bodies out of grains. The linkages are often paradoxical and on all sides overflow simple associations of images. Cinema, precisely because it puts the image in motion, or rather endows the image with self-motion [auto-mouvement], never stops tracing the circuits of the brain. Cinema not only puts movement in the image, it also puts movement in the mind. Spiritual life is the movement of the mind. One naturally goes from philosophy to cinema, but also from cinema to philosophy" $(2000,366)$.

In evoking this notoriously ambiguous and highly debated coupling of the brain and the screen, my claim is that the embodied fabula arises from a realm in which these two remain to be differentiated. This means that the affects, emotions, and cognitions pertaining to the cinematic experience can be discerned but not meaningfully isolated from one another and from the audiovisual cinematic input ("the brain is unity," "the brain is the screen"). Rather than departing from a mode of operation based on isolation and disjunction, the embodied fabula turns to cinematic assemblages based on a recognition of the mutual interdependency and co-constitution of entities traditionally separated in the cognitive-formalist fabula, such as the spectator and the film, linearity and nonlinearity, and the cognitive and the affective. ${ }^{17}$

17 This could possibly also relate to theories redefining cinematic agency. According to such 
In relation to this, two concepts - the cinesthetic subject as developed by Vivian Sobchack (2004) and the surrogate body or Leihkörper of Christiane Voss (2011; $2014 b)^{18}$ - might be useful in resituating the notion of embodied fabula in the actual cinematic experience. For Sobchack and Voss, it is not enough to conceptualize the spectator as an embodied being; the film experience must be seen as capable of producing its own corporality. Following Sobchack, the cinesthetic subject is "constituted at the movies as ambiguously located both 'here' off-screen and 'there' onscreen" $(2004,72)$. In this fashion, cinematic spectatorship arises synesthetically and coenaesthetically, i.e. in and through the whole sensory-mechanisms of the body. ${ }^{19}$ Sobchack's Merleau-Ponty-inspired phenomenological approach to the cinematic experience is, however, not interested in questions about narration but rather investigates the "primary structures, founded in existence and constitutive of conscious experience” (Sobchack 1992, 8).

Where Sobchack thus opposes the phenomenal experience with the semanticcognitive operations involved in narrative comprehension, German filmphilosopher Christiane Voss maintains that illusions (and hence narrative universes) in cinema should be understood in terms of how they emerge from a sensory-affective resonance with the audiovisual stream of images. Drawing upon John Dewey's philosophy of aesthetics, Voss regards the aesthetics of cinema as "an irreducible and simultaneously reciprocally dynamic relation of aesthetic presentation and reception" $(2011,138)$. Voss maintains that cinematic narratives cannot be reduced to a brute cognitive apprehension of a cinematic "text" but arise instead from a "loan body" given to us in the direct cinematic encounter: "My thesis is that it is only the spectator's body, in its mental and sensorial-affective resonance with the events onscreen, which [...] 'loans' a three-dimensional body to the screen and thus flips the second dimension of the film event over into the third dimension of the sensing body. The spectator thus becomes a temporary 'surrogate body' for the screen, and this body is, for its part, a constituent feature of the filmic architecture" (Voss 2011, 145; see also: 2014b, 117).

theories, agency is distributed not only to the spectator, who organizes the narrative, but also to the image in its capability of affecting and moving (cf. Sierek 2007; Engell 2014; Voss 2014a). The term surrogate body is the suggestion made by Inga Pollmann to translate the German noun Leihkörper, which literally brings together the words "loan" and "body" (cf. Voss 2011).

19 As Sobchack explains, besides the word cinema, the term cinesthetic draws on synaesthesia and coenaesthesia. In common usage, synaesthesia refers "not only to an involuntary transfer of feeling among the senses but also to the volitional use of metaphors in which terms relating to one kind of sense impression are used to describe a sense impression of other kinds" $(2004,68)$. Coenaesthesia designates "the potential and perception of one's whole sensorial being" (2004, $68)$. 
The main advantage of Voss's concept of the Leihkörper is that it carves out the connection between levels of description based in the primary structures of Sobchack and those that are based in cognitive-semantics and thus associated with plot, composition, characters, focalization, etc. Removing the fabula from its origin in the cinematic "text" and situating it instead in the cinematic Leihkörper makes it possible to emphasize both its cognitive-symbolic and corporal-affective dimensions without reducing the fabula to either the formal and stylistic features of the film or to the cognitive and affective processes of the brain-body. ${ }^{20}$

Memento allows us to experience cinematic narration as a process which does involve attempts to construct spatio-temporal and causal-linear coherency, yet not in the cognitively-analytically detached fashion automatically assumed by the analytical fabula of cognitive-formalism. Memento's narrative design calls for a conceptual tool capable of bringing forth the resonances that the film provokes in the affect-emotion-cognition circuitry of the cinematic Leihkörper. The embodied fabula allows us to conceptualize the formation of cinematic narration as an amalgamation of the recursive interplay of several modes that are all integral to narrative comprehension. As I have argued in relation to Memento, these include corporal-affectivity (the dizzying temporal sensation, the sense of memory loss, and the loss of narrative unity), the film's emotional landscape, atmosphere, or mood, and the invocation of a particular mode of temporal reorganization connected with narration more broadly. In incorporating the cognitive-symbolic and analytical fabula into an embodied framework that shifts the focus to assemblages of cognitions, emotions, and affects rather than perceiving such according to an analytical principle of disjunction, I hope to have hinted at how the embodied fabula could be a useful conceptual tool for understanding the multimodality behind the narrative powers of Memento, which continues to intrigue cineastes and academics alike.

20 Although this article has focused on the concept of fabula, it is necessary not to forget its counterpart: the syuzhet (understood as the actual arrangement of the visible and audible "events" of the narrative). It can be argued that the syuzhet is equally misconstrued as the cognitive-analytical "facts" that "cue" us into constructing the fabula, since our ability to detect and designate such narrative "events" equally relies on our emotional-affective appreciation of the incoming stimuli. As Patrick Colm Hogan has argued: "Our isolation of something as an event and our attribution of a cause to that event are both crucially a function of emotional response, even if other systems are involved as well” $(2012,16)$. 


\section{Conclusion}

In reference to the complex dramaturgical architecture of Memento, I have proposed a reconceptualization of the cognitive-formalist concept of the fabula. Rather than being merely a perplexing cognitive puzzle, this article suggests that Memento's success should be found in how it embeds us into its themes of amnesia and identity loss. The main task in this relation has been to integrate the corporal and affective aspects of spectatorship as constitutive elements of the fabula rather than mere effects of our cognitive-inferential appropriation of the narrative. To circumvent the problematic disassociation of perception, action, cognition, emotion, and affect associated with the classical sandwich model of narrative comprehension, I have relocated the fabula in a realm irreducible to the spectator and to the film, yet inevitably bound up on both. This I have done in reference to the concepts of the cinesthetic subject (Sobchack) and the Leihkörper (Voss) with the particular aim of reconnecting the initial, phenomenological, and embodied experience with the higher-level cognitive-symbolic operations that I maintain are both vital ingredients for the emergence of narration. Although the scope of this article merely touches upon the outlines of this narratological tool, I hope to have made clear how the embodied fabula may contribute to draw our theoretical understanding of cinematic narration closer to the actual experiences we have in the cinema. Only from such a standpoint can we fully appreciate how films like Memento realize the cinematic potential to enfold viewers into an audiovisual stream of complex temporalities, narrative rhythms, sensational flows, and multiple cognitive-reflexive pathways that demand to be understood in genuinely embodied terms.

\section{References}

Baguer, Ignacio Domingo. 2004. What Time Is It?: New Temporal Regimes in Science-Fiction Cinema. In Memory, Imagination and Desire in Contemporary Anglo-American Literature and Film, eds. Constanza del Río Álvaro and Luis Miguel García Mainar, 245-251. Heidelberg: Universitätsverlag Winter.

Barker, Jennifer M. 2009. The Tactile Eye: Touch and the Cinematic Experience. Berkeley: University of California Press.

Bianco, Jamie Skye. 2004. Techno-Cinema. Comparative Literature Studies vol. 41 no. 3: 377-403.

Bordwell, David. 1985. Narration in the Fiction Film. Madison, Wisconsin: University of Wisconsin Press. 
Bordwell, David. 2006. The Way Hollywood Tells It: Story and Style in Modern Movies. Berkeley; Los Angeles; London: University of California Press.

Bordwell, David. 2007. Poetics of Cinema. New York: Routledge.

Bordwell, David. 2011. Common Sense + Film Theory $=$ Common-Sense Film Theory? David Bordwell's Website on Cinema, May. http://www.davidbordwell. net/essays/commonsense.php. Last accessed 30. 10. 2015.

Brinkema, Eugenie. 2014. The Forms of the Affects. Durham and London: Duke University Press Books.

Brown, William. 2013. Supercinema: Film-Philosophy for the Digital Age. New York and Oxford: Berghahn Books.

Buckland, Warren. 2003. Cognitive Semiotics of Film. Cambridge, Massachusetts and London: Cambridge University Press.

Coëgnarts, Maarten and Peter Kravanja. 2012. Embodied Visual Meaning: Image Schemas in Film. Projections vol. 6 no. 2: 84-101.

Coplan, Amy. 2009. Empathy and Character Engagement. In The Routledge Companion to Philosophy and Film, eds. Paisley Livingstone and Carl Plantinga, 97-110. London and New York: Routledge.

Deleuze, Gilles. 2000. The Brain Is the Screen: An Interview with Gilles Deleuze. In The Brain Is the Screen: Deleuze and the Philosophy of Cinema, ed. Gregory Flaxman, 365-373. Minneapolis: University of Minnesota Press.

Deleuze, Gilles. 2005a. Cinema 1: The Movement-Image. London: Continuum.

Deleuze, Gilles. 2005b. Cinema 2: The Time-Image. London: Continuum.

Elsaesser, Thomas and Malte Hagener. 2009. Film Theory: An Introduction through the Senses. New York: Routledge.

Emmott, Catherine and Marc Alexander. 2009. Schemata. In Handbook of Narratology, eds. Peter Hühn, Jan Christoph Meister, John Pier and Wolf Schmid, 411-419. Berlin: Walter de Gruyter.

Engell, Lorenz. 2014. Agentur. In Essays Zur Film-Philosophie, eds. Lorenz Engell, Christiane Voss, Vinzenz Hediger and Oliver Fahle, 17-61. Munich: Wilhelm Fink Verlag.

Gallagher, Shaun. 2005. How the Body Shapes the Mind. Oxford and New York: Oxford University Press.

Gallese, Vittorio. 2005. Embodied Simulation: From Neurons to Phenomenal Experience. Phenomenology and the Cognitive Sciences vol. 4 no. 1: 23-48. Gallese, Vittorio. 2011. Neuroscience and Phenomenology. Phenomenology \& Mind no. 1: 33-48. 
Gallese, Vittorio and Michele Guerra. 2012. Embodying Movies: Embodied Simulation and Film Studies. Cinema: Journal of Philosophy and the Moving Image no. 3: 183-210.

Gallese, Vittorio, and Hannah Wojciehowski. 2011. How Stories Make Us Feel: Toward an Embodied Narratology. California Italian Studies vol. 2 no. 1: 1-37. Ghislotti, Stefano. 2003. Backwards: Memory and Fabula Construction in Memento by Christopher Nolan. Film Anthology. Internet Review of Film and Cinema. http://dinamico2.unibg.it/fa/fa_mem01.html. Last accessed 30. 10. 2015.

Ghislotti, Stefano. 2009. Narrative Comprehension Made Difficult: Film Form and Mnemonic Devices in Memento. In Puzzle Films: Complex Storytelling in Contemporary Cinema, ed. by Warren Buckland, 87-106. Malden, Massachusetts: Wiley-Blackwell.

Grodal, Torben Kragh. 2009. Embodied Visions: Evolution, Emotion, Culture, and Film. Oxford and New York: Oxford University Press.

Hogan, Patrick Colm. 2012. Affective Narratology: The Emotional Structure of Stories. Lincoln: University of Nebraska Press.

Hurley, Susan L. 2002. Consciousness in Action. Cambridge, Massachusetts: Harvard University Press.

Hurley, Susan L. 2008. The Shared Circuits Model (SCM): How Control, Mirroring, and Simulation Can Enable Imitation, Deliberation, and Mindreading. Behavioral and Brain Sciences vol. 31: 1-58.

Klein, Andy. 2001. Everything You Wanted to Know about Memento. Salon June 28. http://www.salon.com/2001/06/28/memento_analysis/. Last accessed 30. 10. 2015.

Lakoff, George and Mark Johnson. 1999. Philosophy in the Flesh: The Embodied Mind and Its Challenge to Western Thought. New York: Basic Books.

Lazarus, Richard S. 1984. On the Primacy of Cognition. American Psychologist vol. 39 no. 2: 124-129.

Leys, Ruth. 2011. A Turn to Affect: A Critique. Critical Inquiry vol. 37 (Spring): 434-472.

Marks, Laura U. 2000. The Skin of Film: Intercultural Cinema, Embodiment, and the Senses. Durham and London: Duke University Press.

Marks, Laura U. 2002. Touch: Sensuous Theory and Multisensory Media. Minneapolis and London: University of Minnesota Press.

Massumi, Brian. 2002. Parables for the Virtual: Movement, Affect, Sensation. Durham and London: Duke University Press. 
Morin, Edgar. 2007. Restricted Complexity, General Complexity. In Worldviews, Science and Us: Philosophy and Complexity, eds. Carlos Gershenson, Diederik Aerts and Bruce Edmonds, 5-29. River Edge, New Jersey: World Scientific Pub Co Inc.

Nolan, Christopher. 2012. Christopher Nolan: A Visionary's Memento Pt.1. Interview by Dean Kish. MovieSoothsayer. http://moviesoothsayer.wordpress. com/2012/06/27/christopher-nolan-a-visionarys-memento-pt-1/. Last accessed 30. 10. 2015.

Pepperell, Robert. 2003. The Posthuman Condition: Consciousness beyond the Brain. Bristol, UK and Portland, Oregon: Intellect.

Pisters, Patricia. 2014. Dexter's Plastic Brain - Mentalizing and Mirroring in Cinematic Empathy. Cinéma \& Cie. International Film Studies Journal vol. 14 no. 22/23: 53-63.

Pisters, Patricia. 2012. The Neuro-Image: A Deleuzian Film-Philosophy of Digital Screen Culture. Stanford, California: Stanford University Press.

Plantinga, Carl. 1997. Notes on Spectator Emotion and Ideological Film Criticism. In Film Theory and Philosophy, eds. Richard Allen and Murray Smith, 372390. Oxford: Oxford University Press.

Plantinga, Carl. 2009. Moving Viewers: American Film and the Spectator's Experience. Berkeley, Los Angeles and London: University of California Press. Plantinga, Carl and Greg M. Smith. 1999a. Introduction. In Passionate Views: Film, Cognition, and Emotion, eds. Carl Plantinga and Greg M. Smith, 1-17. Johns Hopkins University Press: Baltimore, Maryland.

Plantinga, Carl and Greg M. Smith, eds. 1999b. Passionate Views: Film, Cognition, and Emotion. Johns Hopkins University Press: Baltimore, Maryland.

Prigogine, Ilya and Isabelle Stengers. 1984. Order Out of Chaos: Man's New Dialogue with Nature. New York: Bantam.

Renner, Karen. 2006. Repeat Viewings Revisited: Emotions, Memory, and Memento. Film Studies vol. 8: 106-115.

Shaviro, Steven. 1993. The Cinematic Body. Minneapolis and London: University of Minnesota Press.

Sierek, Karl. 2007. Foto, Kino und Computer. Aby Warburg als Medientheoretiker. Hamburg: Philo Fine Arts.

Sinnerbrink, Robert. 2011. New Philosophies of Film: Thinking Images. London and New York: Continuum.

Sobchack, Vivian Carol. 1992. The Address of the Eye: A Phenomenology of Film Experience. Princeton, New Jersey: Princeton University Press. 
Sobchack, Vivian Carol. 2004. Carnal Thought: Embodiment and Moving Image Culture. Berkeley, Los Angeles, London: University of California Press.

Tan, Ed S. 1996. Emotion and the Structure of Narrative Film: Film as an Emotion Machine. Mahwah, New Jersey: Erlbaum.

Timberg, Scott. 2001. Indie Angst. New Times Los Angeles March 15.

Varela, Francisco J., Evan Thompson and Eleanor Rosch. 1992. The Embodied Mind: Cognitive Science and Human Experience. Cambridge, Massachusetts: MIT Press.

Voss, Christiane. 2011. Film Experience and the Formation of Illusion: The Spectator as 'Surrogate Body' for the Cinema. In Cinema Journal vol. 50 no. 4: 136-150.

Voss, Christiane 2014a. Affekt. In Essays zur Film-Philosophie, ed. Lorenz Engell, Christiane Voss, Vinzenz Hediger and Oliver Fahle: 63-116. Munich: Wilhelm Fink Verlag.

Voss, Christiane. 2014b. Der Leihkörper: Erkenntnis Und Ästhetik Der Illusion. Munich: Wilhelm Fink Verlag.

Ward, Jamie. 2010. The Student's Guide to Cognitive Neuroscience. Hove and New York: Psychology Press.

Wilson, Margaret. 2002. Six Views of Embodied Cognition. Psychonomic Bulletin \& Review vol. 9 no. 4: 625-636.

Yacavone, Daniel. 2015. Film Worlds: A Philosophical Aesthetics of Cinema. New York: Columbia University Press. 